\title{
Multistage Bounded Evolutionary Algorithm to Optimize the Design of Sustainable Photovoltaic (PV) Pumping Irrigation Systems with Storage
}

\author{
Julián Ignacio Monís ${ }^{1}$, Rafael López-Luque ${ }^{1, *}$, Juan Reca ${ }^{2}$ and Juan Martínez ${ }^{2}$ \\ 1 Department of Applied Physics, University of Córdoba, Campus of Rabanales, 14071 Córdoba, Spain; \\ jimopana1999@hotmail.com \\ 2 CIAIMBITAL, Agri-Food Campus of International Excellence CeiA3, Ctra, Department of Engineering, \\ University of Almería, Sacramento s/n, La Cañada de San Urbano, 04120 Almería, Spain; jreca@ual.es (J.R.); \\ jumartin@ual.es (J.M.) \\ * Correspondence: fa1lolur@uco.es
}

Received: 16 January 2020; Accepted: 28 January 2020; Published: 31 January 2020

\begin{abstract}
Small off-grid photovoltaic (PV) pumping irrigation systems with storage tanks are an environmentally friendly, cost effective and efficient way of taking advantage of solar energy to irrigate crops, and they are increasingly being used today. However, finding the optimal design of this type of system is cumbersome since there are many possible designs. In this work, a new heuristic method based on the hybrid approach, which uses search space reduction, is developed and adapted to the optimal design for this type of PV irrigation system. At different stages, the proposed approach iteratively combines a bounding strategy based on the application of engineering rules with the aim of reducing the search space with a genetic algorithm to find the optimal design within this search space. The proposed methodology was applied to minimize the cost of a benchmark case study consisting of a real farm placed in the province of Almería (Spain). The proposed methodology was able to provide a faster and an accurate convergence due to the reduction of the search space. This fact led to a reduced total cost of the system. This study proved that the most sensitive variables were the number of modules and the type of pump, whereas the diameter of the pipe and volume of the storage tank remained more stable.
\end{abstract}

Keywords: irrigation; photovoltaic irrigation; optimization; irrigation design; pumping; storage

\section{Introduction}

The use of renewable energy, such as solar energy, is a suitable measure for coping with the scarcity of fossil fuels and their as sociated problems, such as the emission of Greenhouse Gases (GHG) and their growing impact on global warming and climate change. The use of off-grid photovoltaic pumping irrigation systems has increased recently not only because of their environmental benefits but also because of their economic profitability because the cost of conventional electrification in isolated rural areas is rising, whereas the price of PV cells has dropped in recent decades.

The possibility of storing both water and energy in an elevated reservoir or in the soil is another valuable feature of photovoltaic irrigation systems, although in some cases, battery banks are used to store the energy [1]. In addition, in many crops, water consumption is strongly dependent on radiation [2,3], thus PV energy production and energy consumption can be synchronized so the design of these systems can be simpler and more economically and environmentally efficient.

Different typologies of PV irrigation systems exist, namely those that pump water to an elevated tank or reservoir and direct pumping irrigation systems that transport water directly to the irrigation pipe distribution system. The latter type is less common and more complex to operate, primarily because 
energy production and consumption need to be matched perfectly [4-6] as the capacity of the soil profile to store water is limited, especially in sand dominant or coarse soils. In addition, the flowrate of these systems is usually constant because it depends on the discharge and number of the emitters of the irrigation units, so adopting strategies to adapt the flowrate to the available energy is much more complicated. Different authors have comprehensively analyzed this kind of system in order to propose operation strategies able to match energy supply and demand and optimize their performance [7-10].

The first type of PV irrigation system mentioned is the most common because the bias between the energy supply and demand can be balanced by storing water in an elevated storage tank or reservoir [11]. Despite their advantages, these systems also feature some drawbacks, such as the reservoir investment costs and higher evaporation losses from the reservoir [12].

The sizing of these systems must consider the different parts that comprise the system itself, which makes finding an optimal design a difficult task because there are many options to choose from and all the components of the system are interrelated.

Many authors have developed simulation models of the PV irrigation systems and have tried to find an optimal design by performing a sensitivity analysis. The said procedure is simple, but the number of iterations should be very high in order to find a suitable solution. For example, Glasnovic and Margeta [4] developed a simulation model in order to find the optimal solution by performing a sensitivity analysis. Yahyaoui et al. [13] developed an algorithm for sizing PV irrigation systems for tomato crops. Campana et al. [14] followed a similar approach. Bouzidi [15] also developed a simulation model of the system and used two optimization criteria: The concept of loss of power supply probability (LPSP) for the reliability as sessment and the life cycle cost (LCC) for the economic evaluation. Maleki and Askarzadeh [16] and Maleki and Pourfayaz [17] also used the LPSP concept for different kinds of hybrid PV systems. Hamidat and Benyoucef [11] proposed a systematic procedure for sizing PV irrigation systems with storage.

Due to the complexity of the problem, the use of powerful and robust optimization methods is needed for determining an optimal solution, both from an economic and environmental perspective. More specifically, the use of heuristic methods is the most suitable approach for this problem as heuristic approaches can handle complex global optimization problems. Heuristic methods can be defined as a special type of optimization method based on simple rules, which on many occasions mimic some biological or physical processes, capable of finding a "satisfactory" solution. Albeit this solution is not guaranteed to be optimal [18], it is close enough to the optimum from a practical standpoint.

Several heuristic optimization methods have been applied to optimize the design of different types of PV powered systems. Among them, Maleki et al. [19] applied different PSOs (particle swarm optimization algorithms) to the optimum design of hybrid (PV/wind/Batt) systems. Maleki and Pourfayaz [17] also applied three classic heuristic algorithms and four new metaheuristics to the optimal design of a PV/WT/battery hybrid. Sanchez et al. [20] evaluated the performance of the Particle Swarm Optimizer (PSO) method for the optimal design of a residential hybrid wind-photovoltaic-fuel power plant in Mexico.

Regarding the specific case of stand-alone PV pumping systems with water storage, Bakelli and Kaabeche [21] proposed different metaheuristics, such as ant lion optimizer (ALO), bat algorithm (BA), cuckoo search algorithm (CSA) and gray wolf optimization algorithm (GWO). They concluded that the GWO algorithm outperformed the other algorithms. Olcan [22] developed a multi-objective model that considered both the reliability and cost as objectives. On the other hand, EL-Shimy [23] preferred to apply an efficient non-conventional direct method.

Genetic or evolutionary algorithms are perhaps the most well known and widely used heuristic methods and they have also been applied to the PV pumping design problem. For example, Dufo-López and Bernal-Agustín [24] and Carroquino et al. [25] used a Genetic Algorithm (GA) to design a hybrid PV-diesel system. Ma et al. [26] also used a GA to optimize the design of a solar photovoltaic system with pumped storage. Mérida et al. [27] proposed a multiobjective approach and developed a model called MOPISS that used a Non-dominated Sorting Genetic Algorithm (NSGA-II) for the optimal sizing of a PV irrigation system. 
Despite their valuable advantages, the accuracy of heuristic methods and their convergence speed decrease as the size of the optimization problem increases. This inefficiency occurs because general purpose heuristic algorithms must explore a vast search space, and thereby devote a great effort to evaluating unfeasible solutions. To overcome this drawback, Reca et al. [28] proposed a new hybrid evolutionary algorithm that was applied to the optimal design of a pipe network. This approach reduced the search space thus increasing both the convergence speed and accuracy of the solution.

In this study, a new heuristic method based on the hybrid approach using search space reduction is developed and adapted to the optimal design of stand-alone PV irrigation pumping systems with a storage tank. The proposed approach is based on iteratively reducing the search space by applying engineering-based rules to the problem with the aim of reducing the number of possible scenarios to analyze. The proposed methodology has been applied to minimize the cost of a benchmark case study. The proposed case study consisted in finding the optimal design of a stand-alone PV irrigation system for an olive orchard farm located in Tabernas (Almería).

\section{Materials and Methods}

\subsection{Overall Description of the Optimal Design Approach}

The system is composed of a photovoltaic array, a frequency converter, a variable speed pump and an elevated tank or reservoir that stores water with enough elevation to distribute it to the irrigation system. A scheme of the PV pumping system analyzed in this work is illustrated in Figure 1.

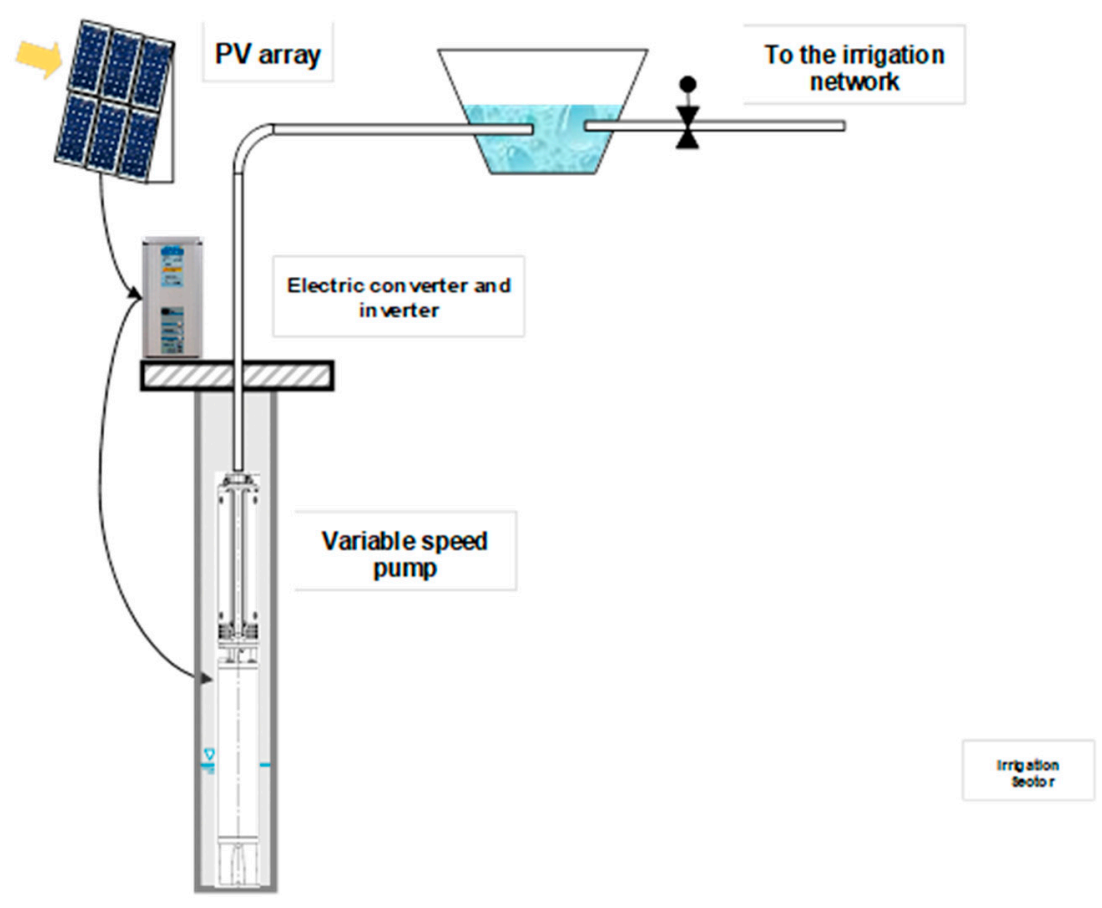

Figure 1. Scheme of the photovoltaic pumping irrigation system.

The decision variables that must be optimized are the following:

1. Diameter of the delivery pipe

2. Pump model

3. Capacity of the elevated tank

4. Number of PV modules.

The proposed optimal design method is composed of a simulation model of the PV irrigation pumping system and an optimization module based on a heuristic approach. These models are described hereafter. 


\subsection{Simulation of the PV Pumping System}

\subsubsection{PV Subsystem}

The PV subsystem model estimated the net photovoltaic power provided by the PV generator $\left(P_{P V}\right)$ depending on the calculated incoming irradiance. An isotropic distribution of the diffuse radiation [29] was supposed in order to calculate the temporal distribution of the irradiance, $I(t)$. The model by Collares-Pereira and Rabl [30] was applied to disaggregate direct and diffuse irradiance from the global daily radiation in $\mathrm{MJ} \mathrm{m}^{-2}$. A detailed description of the calculation procedure is further described in previous works $[7,31]$.

\subsubsection{Pumping Subsystem}

The pumping system can be described by both the performance curves and the system curve. In this work, the Head-Discharge (H-Q) and Power-Discharge (P-Q) performance curves of the pump for its nominal rotational speed are given as the input data of the problem. These curves can be fitted to second degree polynomial functions and are shown in the following set of equations.

$$
\begin{aligned}
H & =A \cdot Q^{2}+B \cdot Q+C \\
P & =E \cdot Q^{2}+F \cdot Q+G
\end{aligned}
$$

where: $H$ is the pumping head $(\mathrm{m}), Q$ is the pump discharge $\left(\mathrm{m}^{3} \mathrm{~s}^{-1}\right)$ and $P$ is the pumping power. A to $C$ and $E$ to $G$ are regression coefficients.

The performance of the pump depends on not only the type of pump but also on its working speed. The performance of a variable speed pump can be modelled by applying affinity laws that are shown in the following set of equations:

$$
\left.\begin{array}{l}
\frac{N_{1}}{N_{2}}=\frac{f_{1}}{f_{2}}=\frac{Q_{1}}{Q_{2}}=\lambda \\
\frac{H_{1}}{H_{2}}=\frac{Q_{1}^{2}}{Q_{2}^{2}}=\lambda^{2} \\
\frac{P_{1}}{P_{2}}=\left(\frac{H_{2}}{H_{2}}\right)^{\frac{3}{2}}=\lambda^{3}
\end{array}\right\}
$$

where: $N_{1}$ and $N_{2}$ are two specific pump speeds (in rpm) 1 and 2, $f_{1}$ and $f_{2}$ are the electric frequency, $Q_{1}$ and $Q_{2}$ are the pump discharges, $H_{1}$ and $H_{2}$ are the pumping heads and $P_{1}$ and $P_{2}$ are the pumping power for these two specific pump speeds. $\lambda$ is the pump speed ratio.

The system curve $(\mathrm{H})$ is given in Equation (3):

$$
H=\Delta z+h f
$$

where: $\Delta z$ is the static head, i.e., elevation change between the water level in the suction of the pump and the water level in the elevated tank $(\mathrm{m}), h_{f}$ is the friction head, i.e., the total head losses in the delivery pipe (m).

Pressure losses were calculated by applying the Darcy-Weisbach equation [32].

$$
h f=8 \cdot f_{p} \cdot \frac{L}{D^{5}} \cdot \frac{Q^{2}}{g \cdot \pi^{2}}
$$

where: $f_{p}$ is the friction factor of the pipe, which in turn depends on the relative roughness of the pipe and the Reynolds number, $L$ is the length of the pipe, $D$ is the diameter and $Q$ is the total discharge.

The net power transferred to the water by the pump is equal to:

$$
P_{i}=\gamma \cdot Q \cdot H
$$

where: $\gamma$ is the specific weight of the water $\left(\mathrm{N} \mathrm{m}^{-3}\right)$. 
The total PV power required to drive the pump is estimated by applying Equation (6):

$$
P_{P V}=\frac{P_{i}}{\eta_{P} \cdot \eta_{A M} \cdot \eta_{F C}}
$$

where: $\eta_{F C}$ is the efficiency of the converter, $\eta_{A M}$ is the efficiency of the asynchronous motor and $\eta_{P}$ is the pump efficiency.

\subsubsection{Water Balance}

The irrigation water demands were calculated using the methodology proposed by FAO [33]. The crop evapotranspiration $\left(E T_{\mathcal{c}}\right)$ was calculated applying Equation (7):

$$
E T_{c}=E T_{o} \cdot K_{c} \cdot K_{r}
$$

where: $E T_{o}$ is the reference evapotranspiration and $K_{c}$ is the crop coefficient and $K_{r}$ is a reduction coefficient for sparse crops with limited canopy cover.

In this study, $E T_{o}$ was computed applying the Penman-Monteith formula. The net irrigation requirements, $N_{n},(\mathrm{~mm})$ can be estimated as the difference between $E T_{c}$ and the effective precipitation [34], meaning rainfall that is effectively used by the crop $\left(P_{e}\right)$.

Finally, the gross irrigation water requirements $\left(N_{g}\right.$, in $\left.\mathrm{mm}\right)$ can be calculated as a function of the $N_{n}$ by applying an irrigation efficiency $\left(\eta_{a}\right)$ in order to take into account the water losses in the system (See Equation (8)).

$$
N_{g}=\frac{N_{n}}{\eta_{a}}
$$

A model to calculate irrigation water requirements previously developed by the authors and applied in previous works was used in this research.

The water volume $\left(V_{R i}\right.$, in $\left.\mathrm{m}^{3}\right)$ needed to irrigate a farm with an area $S$ (ha) during a specific period $i$ can be calculated as a function of the gross irrigation requirements for that period $\left(N_{g i}\right)$ as shown in Equation (9):

$$
V_{R i}=N_{g i} \cdot S \cdot 10
$$

The water volume pumped to the reservoir $\left(V_{P i}\right.$, in $\left.\mathrm{m}^{3}\right)$ for a specific period $i$ can be calculated by multiplying the pumping flowrate $\left(Q_{i}\right.$, in $\left.\mathrm{m}^{3} / \mathrm{s}\right)$ by the pumping time $\left(T_{i}\right.$, in $\left.\mathrm{s}\right)$. The volume of water stored in the tank can be modelled by applying a water balance model:

$$
\begin{gathered}
V_{i}=V_{i-1}+V_{P i}-V_{R i} \\
\text { if } V_{i} \geq 0 \rightarrow I D_{i}=0 \\
\text { if } V_{i} \leq 0 \rightarrow V_{i}=0 ; I D_{i}=-V_{i-1}-V_{P i}+V_{R i}
\end{gathered}
$$

where: $V_{i}$ and $V_{i-1}$ are the volume of water stored in the reservoir in periods $i$ and $i-1$, respectively, $I D_{i}$ is the irrigation deficit in period $i$. The volume stored in the reservoir must be lower than the maximum capacity of the tank.

\subsection{Statement of the Optimization Problem}

A multistage bounded genetic algorithm module was applied to optimize the design of the PV pumping system. The GA algorithm developed in this work is based on the GENOME (University of Almería, Almería, Spain) software model developed by Reca and Martínez [35], which was later converted in B-GENOME [28], an improved bounded version of GENOME that was applied to optimize the cost of a pipe network. This code was modified and adapted with the aim of optimizing the above-mentioned PV pumping design problem (BPV-GENOME). The latter model was developed using the VBA programming language and embedded in an EXCEL ${ }^{\odot}$ (Microsoft Corporation, Redmond, Washington, EE.UU) workbook. 
B-GENOME used an efficient integer-coding scheme. Each individual (possible solution) is described by a chromosome consisting of a vector of $n$ discrete variables (genes). Genes were codified by an integer value ranging from one to $n_{i}$ (maximum number of possible values as signed to the variable $i$, i.e., alleles). This coding scheme was also adopted in BPV-GENOME, in which case the chromosome is composed of four genes, one per decision variable. The first gene codifies the diameter of the pipe, the second gene codifies the type of pump, the third one the capacity of the tank and the last one the number of PV modules. The number of alleles per gene depends on the input data of the problem. The number of alleles of the first and second gene depends on the total number of pipe diameters in the input pipe database and the number of pumps in the pump database, respectively. The third and fourth variables have a few alleles that results from a predefined minimum and maximum value of each variable (volume of the tank and number of PV modules, respectively) and a variable step. The bounding strategy used in this work is described hereafter.

\subsubsection{Multistage Bounding Strategy}

A multistage bounding strategy is proposed in this study with the aim of reducing the search space and improving the efficiency of the GA algorithm. The initial set-up of the limits of the variables is done by applying engineering-based rules. In this initial stage, the aim is to apply relatively wide bounds, so that the resulting reduced search space includes not only the problem solution but also its surroundings, which may provide useful information. Individuals that are clearly beyond the limits and drastically violate the problem's restrictions are simply discarded to reduce the complexity of the problem. The steps in this initial bounding are described as follows:

(a) Bounding the diameter series:

Maximum and minimum reasonable pipe diameters are estimated depending on the flow range required by the irrigation system. The first step is to calculate the fictitious continuous flow (q), which is defined as the flowrate required to supply the maximum crop water requirement if the pumping system operates continuously during the whole day. The maximum flow is obtained multiplying the fictitious continuous flow by a degree of freedom (DF), which indicates the number of times that the system would be able to supply the required irrigation water in a day. The higher the selected value of the degree of freedom, the wider the bound for the maximum flow (see Equation (11)).

$$
Q_{M}=q \cdot D F=\frac{N_{g} \cdot S \cdot 10}{24} \cdot D F
$$

where: $q\left(\mathrm{~m}^{3} / \mathrm{s}\right)$ is the continuous flow, $D F$ is the degree of freedom (dimensionless) and $Q_{M}\left(\mathrm{~m}^{3} / \mathrm{s}\right.$ ) is the maximum pumped flow.

To calculate the diameter bounds, velocity restrictions are imposed on the flow in the pipes. Excessively high flow velocities in the pipe may produce pipe erosion, loud noise, undesired effects of hydraulic transients and excessive head losses. On the contrary, very low velocities may produce sedimentation and oversizing of the system. Maximum $\left(D_{M}\right)$ and minimum $\left(D_{m}\right)$ diameter sizes can be calculated by applying these velocity restrictions in the pipe. $D_{M}$ is limited to the diameter able to supply the maximum flow with the minimum admissible flow velocity in the pipe. $D_{m}$ is defined as the size of the pipe that would supply the continuous flow with the maximum admissible velocity in the pipe (see Equation (12)). Diameters in the pipe database out of this range are neglected.

$$
\begin{aligned}
& D_{M}=\sqrt{\frac{4 \cdot \frac{Q_{M}}{\pi 600}}{\pi \cdot U_{m}}} \\
& D_{m}=\sqrt{\frac{4 \cdot \frac{q}{3600}}{\pi \cdot U_{M}}}
\end{aligned}
$$

(b) Bounding the pump series: 
The admissible pump series are calculated by performing the procedure depicted in Figure 2 as a function of the bounded pumped flows and pumping heads.

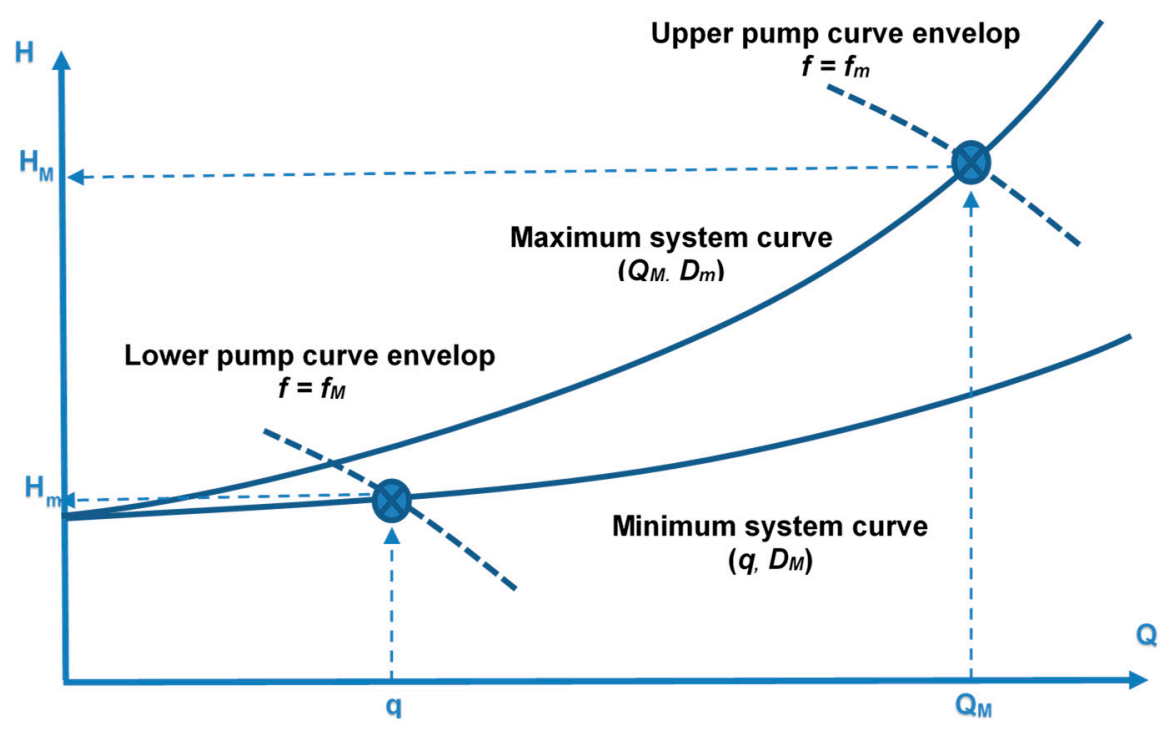

Figure 2. Elective series of pumps.

Extreme maximum and minimum system curves are defined for the maximum pumped flow $\left(Q_{M}\right)$ and continuous flow $(q)$, respectively. These curves were computed by applying Equations (3) and (4). Two extreme operating points, $\left(Q_{M}, H_{M}\right)$ and $\left(q, H_{m}\right)$, are thus defined. These points are used to limit the range of admissible pumps. Admissible pumps are those whose performance curves lie within two envelopes. The upper envelope requires that the performance $\mathrm{H}-\mathrm{Q}$ curve of the pump falls below the maximum operating point with the pump operating at the minimum frequency (rotating speed). Pumps above this limit would produce operating points far beyond the upper limit. The lower envelope requires that the pump curve falls above the lower operating point operating at its maximum speed. Pumps with H-Q curves below this limit are clearly unable to supply the flow and energy demands.

(c) Bounding the capacity of the storage tank:

Maximum and minimum capacity levels are defined. The minimum capacity of the tank was set to the volume of water needed to irrigate for one day. This volume makes it possible to have a minimum water storage in case the PV pumping system fails. The maximum capacity was set to the volume equal to 30 days of water consumption. Higher volumes are considered excessive. The volume step is equal to one day of storage so that 30 possible storage volumes (multiple of the minimum volume to store one day of operation) are considered in this initial bounding.

(d) Bounding the PV power:

The maximum and minimum number of PV modules are calculated depending on the power required to drive the most and least powerful pumps in the selected series of admissible pumps. Required PV power for both cases can be calculated by applying the appropriate inverter and motor efficiencies (Equation (6)). If the difference between the maximum and minimum number of modules is lower than 50 , the step equals one module. The maximum number of steps was set to 50 so if the difference is higher, the step can be higher than one module.

After this initial bounding is performed, the GA algorithm is applied recursively (in this work ten runs of the GA were performed). The solutions of this first GA phase provide the range of solutions that serve to refine the search space and redefine the problem limits in the subsequent stage. Since the solution space is now narrower, the number of PV modules and capacity of the tank steps 
are now smaller. After a second round of GA analyses, a new more precise solution with higher resolution can be found. In this work, two stages were performed, although more iterative stages can be also conducted.

\subsubsection{Genetic Algorithm}

Genetic algorithms (GA) are heuristic methods that mimics the evolutionary mechanisms of natural selection and genetics [18]. Genetic algorithms are based on the effective optimization model that has naturally evolved for dealing with large, highly complex systems.

In the GA formulation, the initial population is obtained randomly. Using a random generator, integer values are generated, ranging from 1 to $n_{j}$, where $n_{j}$ is the number of alleles of each gene. Then, population evolves by undergoing an iterative reproductive cycle in subsequent generations. This evolutive cycle is composed of three basic operators: Selection, crossover and mutation. There are many possible methods to perform these basic operations: The selection operator used in this work is called steady-state-delete-worst plan. According to this plan, a new individual is inserted in the population if its fitness exceeds that of the least fit member of the parent population. That least fitted individual is consequently removed and replaced by the offspring. The crossover process involves the exchange of information between two parent chromosomes to produce two new offspring chromosomes that inherit their characteristics. This process is controlled by the input parameter $p_{\text {cross }}$, which defines the probability of crossing two chromosomes. In this work, a uniform crossover procedure was applied, meaning that the parents' chromosomes exchange information gene to gene. A gene crossing rate $\left(r_{\text {cross }}\right)$ parameter is defined with the aim of defining the probability of exchanging a specific gene. Finally, a mutation probability $\left(P_{m u t}\right)$ is defined to specify the mutation rate. The mutation operator swaps the allele of the selected gene with a randomly generated value.

A population size of 50 individuals and 50 generations was selected in this work because it provided a good trade-off between convergence speed and accuracy. The remaining GA parameters and options used in this work are summarized in Table 1 and were recommended in other works [28,35].

Table 1. Input parameters for the genetic algorithm.

\begin{tabular}{cc}
\hline Parameter & Value \\
\hline Population $\left(\mathrm{n}_{\mathrm{p}}\right)$ & 50 \\
Generations $\left(\mathrm{n}_{\mathrm{g}}\right)$ & 50 \\
Crossover prob. $\left(\mathrm{p}_{\text {cross }}\right)$ & 0.9 \\
Mutation prob. $\left(\mathrm{P}_{\text {mut }}\right)$ & 0.05 \\
Prob. of gene crossing $\left(\mathrm{r}_{\text {cross }}\right)$ & 0.5 \\
Reproduction plan & steady-state-delete-worst plan \\
Crossover operator & uniform crossover \\
\hline
\end{tabular}

\subsubsection{Objective Function}

For every generation, the fitness of every individual is evaluated. This fitness is defined as the sum of the cost of the system (cost of the delivery pipe, cost of the pump, cost of the tank and cost of the PV plant) plus a penalty function to consider the supply deficit. A supply deficit occurs when one specific induvial (system design) is unable to supply the target water demands for irrigation (see Equation (13)).

$$
F F=C_{D}+C_{P}+C_{S}+C_{P V}+K_{P} \cdot I D
$$

where: $F F=$ fitness function, $C_{D}=$ cost of the pipe, $C_{P}=$ cost of the pump, $C_{S}=$ cost of the storage tank, $C_{P V}=$ cost of the PV plant, $K_{P}=$ penalty multiplier and $I D=$ cumulative water deficit in the system (sum of deficits for every study period).

The penalty multiplier $\left(K_{P}\right)$ may affect the convergence and accuracy of the GA algorithm, so the value of this parameter should be adjusted. Some researchers recommend different constraint-handling 
techniques, such as the use of variable values or self-adaptive penalty functions [36]. However, in this work, a high value $\left(10^{9} € / \mathrm{m}\right)$ was selected for this parameter to discard infeasible solutions that imply an insufficient irrigation water supply.

\subsection{Structure of the BPV-GENOME Model}

The flowchart of the BPV-GENOME (Bounded Photovoltaic irrigation-GENOME) model is depicted in Figure 3.

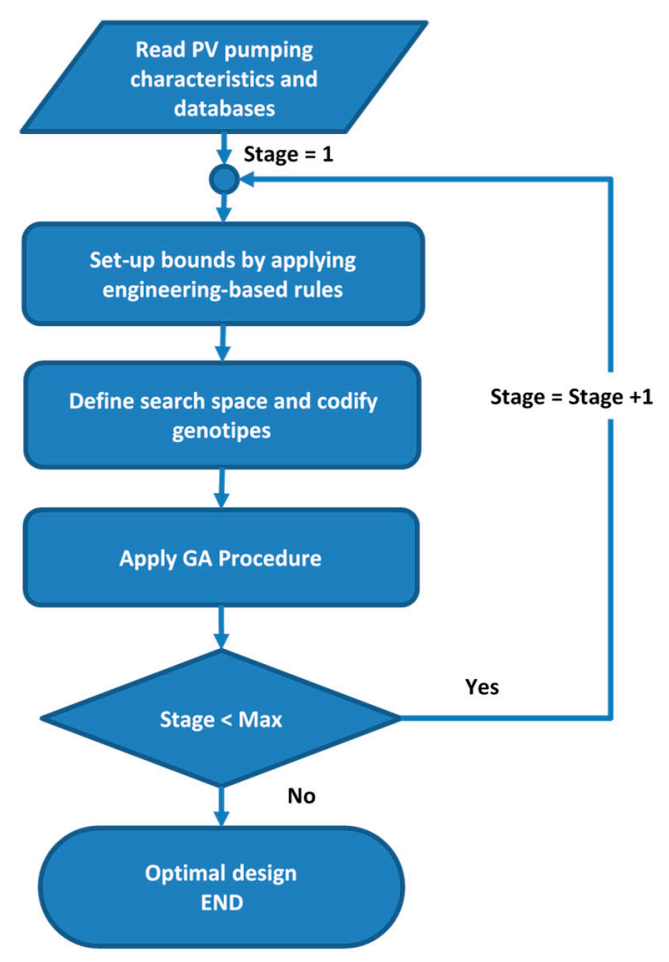

Figure 3. Flow chart of the model BPV-GENOME (Bounded Photovoltaic irrigation-GENOME).

The model BPV-GENOME is composed of several modules: An input/output module, a GA module, a PV pumping simulation model and a bounding module. The model was programmed in the EXCEL ${ }^{\odot}$ spreadsheet platform using the VBA programming language. The input module reads the general input data of the problem and the specific databases, i.e., the pipe database and the pump database. These databases are stored in EXCEL ${ }^{\circledR}$ sheets. These databases contain the basic characteristics of the pipe and pump series and their as sociated costs. The output module writes the final solution found by the model (optimal combination of pipe diameter, pump unit, storage capacity and PV peak power) and the best fitness function value for every generation in a results spreadsheet.

\subsection{Case Study}

A specific case study was used in order to test the methodology. This case study consisted in finding the optimal design of a PV irrigation system for an olive farm in Tabernas, in the province of Almería (Southeast of Spain). A description of the area and the characteristics of the farm can be found in Zavala et al. [37].

The location of the PV plant is $37^{\circ} 06^{\prime}$ north latitude and $02^{\circ} 18^{\prime}$ west longitude and its elevation is 435 meters above sea level. A fixed PV frame was considered with a tilt angle of $20^{\circ}$, the azimuth is $0^{\circ}$ and the albedo is 0.2 . Conventional crystalline cells were used in this study. The peak power per module was $275 \mathrm{~W}$ and the cost of the PV plant was supposedly $0.5 € / \mathrm{PW}$.

The calculated irrigation water requirements are given in Table 2 for the whole farm. 
Table 2. Input parameters for the genetic algorithm.

\begin{tabular}{cc}
\hline Month & Irrigation Requirements $\mathbf{~}^{\mathbf{3}} \mathbf{d a y}^{\mathbf{- 1}} \mathbf{)}$ \\
\hline January & 0.0 \\
February & 0.0 \\
March & 6.8 \\
April & 94.9 \\
May & 156.7 \\
June & 255.0 \\
July & 311.2 \\
August & 273.4 \\
September & 113.2 \\
October & 64.0 \\
November & 0.0 \\
December & 0.0 \\
\hline
\end{tabular}

The water is pumped from a well to an elevated tank with a static head of $38 \mathrm{~m}$. The total length of the pipe from the well to the tank is $420 \mathrm{~m}$.

The pipe series is composed of 14 PVC pipes with different diameter sizes taken from a major manufacturer. The working pressure of the selected pipes was $10 \mathrm{at} \mathrm{m}$. The relative roughness of the pipe was $0.0015 \mathrm{~mm}$. The pipe database is supplied as a supplementary material.

The pump database is composed of 229 different pump units. This database includes submerged pumps of 4 and 6 inches. These pumps differ in the impeller type and the number of impellers per pump unit. This database was taken from an international pump manufacturer and it is also supplied as a supplementary material.

The overall efficiency of the system, comprising the pump, inverter and PV array efficiencies was considered equal to 0.5 . In this research, a constant pump efficiency was assumed.

For the storage tank, a reservoir constructed of excavated natural earth and lined with a plastic sheet was considered. The cost function of this type of reservoir was obtained by fitting unitary cost data provided by an experienced consulting company (see Figure 4).

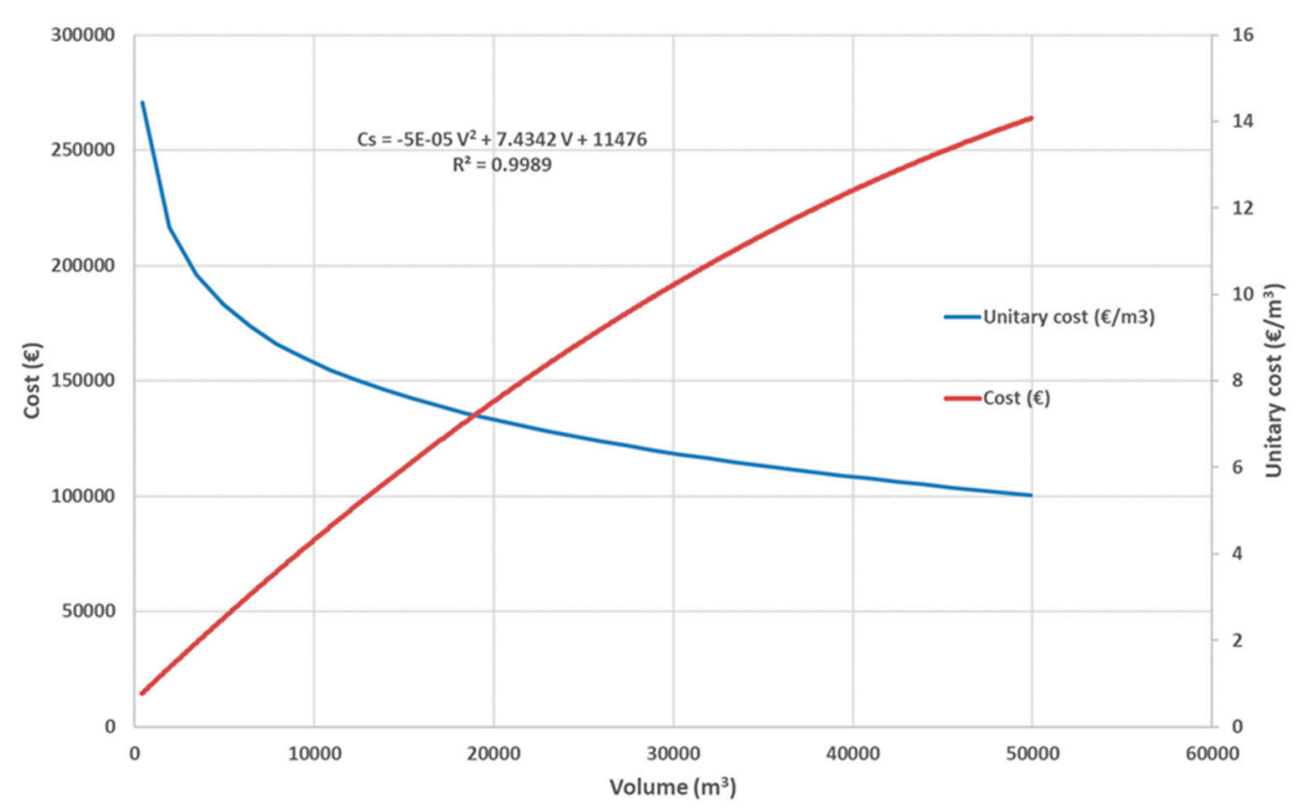

Figure 4. Cost of the storage reservoir. 


\section{Results}

\subsection{First Stage}

\subsubsection{Bounding Results}

After applying the proposed bounding algorithm in this first stage to the optimal design of the case study, the following ranges of variables are obtained. The selected pipe series was reduced to a total of 11 admissible diameter pipes (out of 14 total diameters), ranging from a minimal inner diameter of $57 \mathrm{~mm}$ (PVC 63) to a maximum diameter of $290.8 \mathrm{~mm}$ (PVC 315). The series of admissible pumps was reduced to 161 pump units (out of 229). Regarding the capacity of the storage tank, the volume was discretized in 30 steps of $400 \mathrm{~m}^{3}$, which represents the volume required to supply the irrigation amount of one day of operation during the peak period. The capacity ranged from a minimum of $400 \mathrm{~m}^{3}$ to a maximum of $12,000 \mathrm{~m}^{3}$ (volume needed for 30 days of operation). The number of PV modules was limited to 50 cases, ranging from 0 to 1050 PV modules with a step of 21 modules.

The chromosome of every individual is then composed of an array of four genes (four integer numbers). The first gene was codified by an integer number ranging from 1 to 11 (selected pipe diameter series); the second one from 1 to 161 (selected pump series); the third one ranged from 1 to 30 (volume steps) and the last one from 1 to 50 (number of PV arrays steps). The limited search space had a total size of 2,656,500 combinations.

\subsubsection{Fitness Function}

The GA analysis performed in this first stage yielded the results shown in Figure 5 and Table 3. Figure 5 shows the evolution of the fitness function for ten iterative simulations. Convergence was quickly reached and the optimal fitness function value (optimal cost) ranged from a minim value of $34,142.2 €$ to a maximum of $41,731.7 €$. The average minimum cost in the ten runs was $36,726.3 €$ with a coefficient of variation of $5.2 \%$.

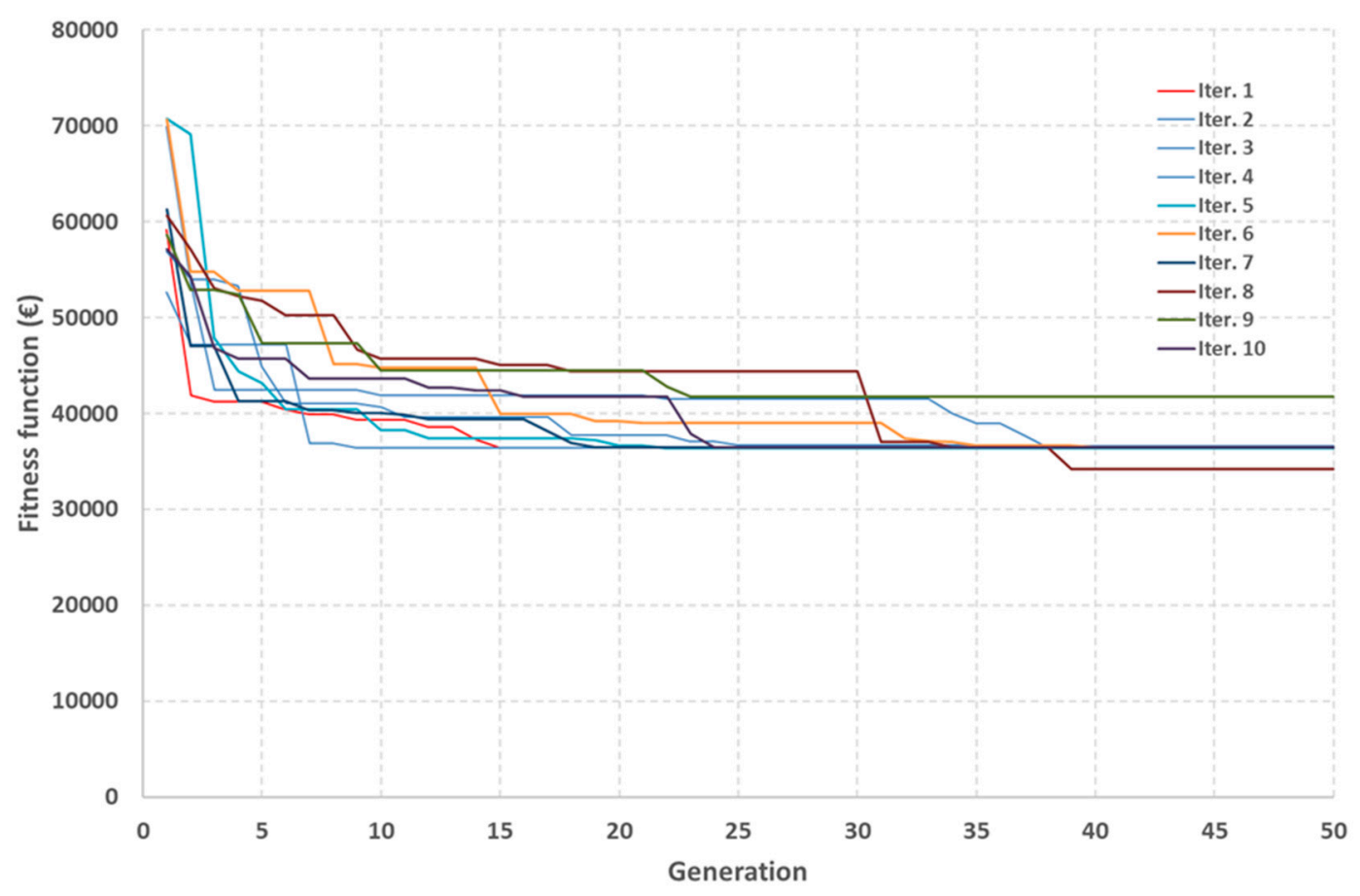

Figure 5. Evolution of the fitness function during the first stage for ten iterative runs. 


\subsubsection{First Stage Results}

The diameter of the pipe that appeared most frequently was 101.6 ( 8 out of 10 times). The type of pump varied among the iterations. Pumps 123 and 125 were chosen three times and other ones were selected once or twice at most, meaning the choice of pump is a sensitive variable. The number of PV modules ranged from $42(11.55 \mathrm{kWp})$ to $105(28.87 \mathrm{kWp})$. The number of modules that were most repeated (seven times out of ten) was $63(17.32 \mathrm{kWp})$. The storage capacity was always $800 \mathrm{~m}^{3}$, which is close to the minimum storage capacity.

Table 3. Solutions provided for the model in the first stage and for ten successive runs.

\begin{tabular}{ccccccccccc}
\hline Design Variable & \multicolumn{10}{c}{ Iteration } \\
\cline { 2 - 11 } & $\mathbf{1}$ & $\mathbf{2}$ & $\mathbf{3}$ & $\mathbf{4}$ & $\mathbf{5}$ & $\mathbf{6}$ & $\mathbf{7}$ & $\mathbf{8}$ & $\mathbf{9}$ & $\mathbf{1 0}$ \\
\hline $\mathrm{D}(\mathrm{mm})$ & 101.6 & 101.6 & 101.6 & 101.6 & 101.6 & 101.6 & 101.6 & 101.6 & 101.6 & 101.6 \\
Peak power $(\mathrm{kWp})$ & 17.32 & 17.32 & 17.32 & 17.32 & 17.32 & 17.32 & 17.32 & 11.55 & 28.87 & 28.87 \\
$\mathrm{~N}^{\mathrm{o}}$ Modules & 63 & 63 & 63 & 63 & 63 & 63 & 63 & 42 & 105 & 105 \\
${\text { Volume }\left(\mathrm{m}^{3}\right)}^{3}$ & 800 & 800 & 800 & 800 & 800 & 800 & 800 & 800 & 800 & 800 \\
Pump ID. & 75 & 123 & 123 & 76 & 123 & 125 & 75 & 125 & 70 & 125 \\
\hline
\end{tabular}

\subsection{Second and Last Stage}

\subsubsection{Bounding Results}

A second stage was performed to improve the accuracy and resolution of the solution. The series of pipe diameters and pumps were not modified in this stage. Regarding the storage volume, the variable was discretized in 50 possible values, starting from 400 and continuing to $1400 \mathrm{~m}^{3}$ with a step of $20 \mathrm{~m}^{3}$. The center of this interval coincides with the solution provided in the first stage $\left(800 \mathrm{~m}^{3}\right)$. Applying a similar procedure, the number of modules varied from 40 to 140 with a step of two modules.

\subsubsection{Fitness Function}

The GA analysis performed in this stage yielded the results shown in Figure 6 and Table 4. Figure 6 shows the evolution of the fitness function for the ten iterative simulations. Convergence was reached fast after the 50 generations. The optimal fitness function value (optimal cost) ranged from a minim value of $30,994.5 €$ (almost $10 \%$ lower than in the first stage) to a maximum of $32,830.5 €$. The average minimum cost in the ten runs was $31,773.8 €$ (an improvement of almost $14 \%$ of the first stage) with a coefficient of variation of only $2 \%$. Considerable cost reductions were achieved in performing this second stage.

\subsubsection{Second Stage Results}

As expected, the optimal diameter of the pipe was $101.6 \mathrm{~mm}$, precisely as in the first stage. The type of pump varied among iterations. Pump 123 was chosen three times; 167 and 125, twice; and pumps 166, 124 and 126, once. Thus, the choice of pump is a more sensitive variable. The number of PV modules ranges from 42 to 52 . The number of modules that were selected more times (four out of ten) was $42(11.55 \mathrm{kWp})$. The storage capacity ranged from $420 \mathrm{~m}^{3}$ to $460 \mathrm{~m}^{3}$, although the most common capacity was 420 (6 out of ten). 


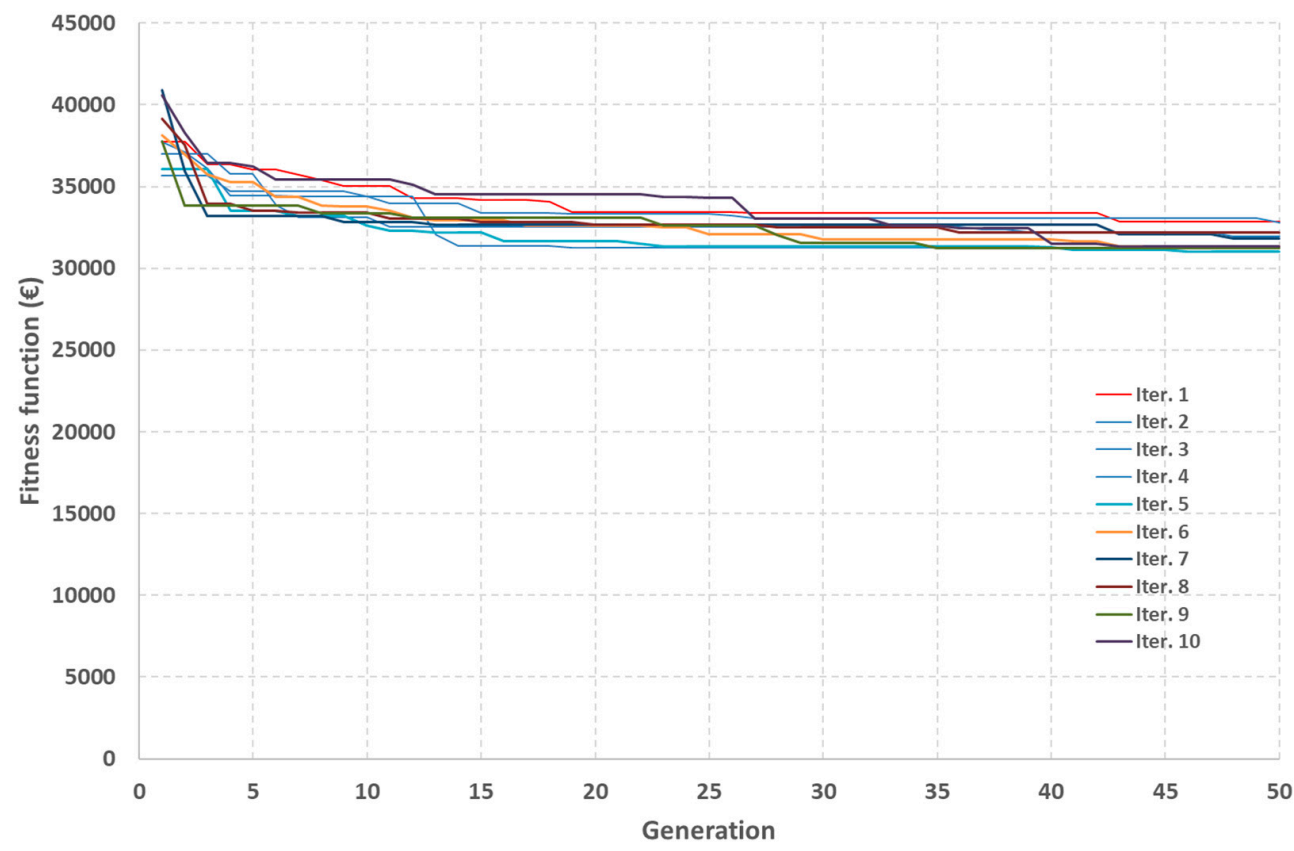

Figure 6. Evolution of the fitness function during the first stage for ten iterative runs.

Table 4. Solutions provided for the model in the first stage and for ten successive runs.

\begin{tabular}{ccccccccccc}
\hline Design Variable & \multicolumn{10}{c}{ Iteration } \\
\cline { 2 - 12 } & $\mathbf{1}$ & $\mathbf{2}$ & $\mathbf{3}$ & $\mathbf{4}$ & $\mathbf{5}$ & $\mathbf{6}$ & $\mathbf{7}$ & $\mathbf{8}$ & $\mathbf{9}$ & $\mathbf{1 0}$ \\
\hline D (mm) & 101.6 & 101.6 & 101.6 & 101.6 & 101.6 & 101.6 & 101.6 & 101.6 & 101.6 & 101.6 \\
Peak power $(\mathrm{kWp})$ & 14.30 & 12.65 & 11.55 & 12.65 & 11.55 & 11.55 & 13.20 & 12.10 & 12.65 & 11.55 \\
$\mathrm{~N}^{\mathrm{o}}$ Modules & 52 & 46 & 42 & 46 & 42 & 42 & 48 & 44 & 46 & 42 \\
${\text { Volume }\left(\mathrm{m}^{3}\right)}^{4}$ & 420 & 420 & 440 & 460 & 420 & 420 & 460 & 420 & 420 & 420 \\
Pump ID. & 166 & 123 & 126 & 167 & 124 & 125 & 123 & 167 & 123 & 125 \\
\hline
\end{tabular}

\subsection{Final Optimal Design}

Due to the stability and sufficiently high resolution of the solutions found in the second stage, a third stage was considered unnecessary. The optimal design of the system was that which provided the minimum cost in the second stage (see Table 5).

The proposed methodology was able to provide a much faster and accurate convergence to the optimum because of the considerable reduction of the search space achieved.

It is relevant to note that in the minimum cost solution found, the storage volume tends to be close to the minimum because, as the storage capacity increases, the raise in the cost of the tank exceeds the reduction in the pumping and PV costs. However, this low storage capacity causes much of the PV energy to be wasted, thereby yielding a lower Energy Use Efficiency (EUE). In the following section, a more in-depth analysis of the resulting EUE is conducted and appropriate measures for improving this energy efficiency are proposed.

Table 5. Solutions provided for the model in the first stage and for ten successive runs.

\begin{tabular}{cc}
\hline Design Variable & Optimal Design \\
\hline Delivery pipe & $\mathrm{D}_{\mathrm{i}}=101.6 \mathrm{~mm}($ PVC 110) \\
PV plant & Peak power $=11,550 \mathrm{~W}(42$ modules $)$ \\
Tank & Volume $=420 \mathrm{~m}^{3}$ \\
Pump type & $6 \mathrm{BHE}(\mathrm{L}) * 32$ series.6 impellers \\
\hline
\end{tabular}

Note: *6BHE(L) stands for 6" BOREHOLE CENTRIFUGAL PUMPS. 


\subsection{Energy Use Efficiency (EUE)}

With the aim of evaluating the performance of the system from an environmental standpoint, an efficiency index was calculated. The energy use efficiency (EUE) index is defined as the fraction of the maximum energy potentially generated by the PV system that is effectively used (see Equation (14)). The effectively used energy is computed as the potential energy gained by the water pumped to the tank.

Higher values of EUE implies a more efficient use of the solar energy. Energy losses include the energy potentially produced but not instantaneously consumed, energy losses in the motor, inverter and pump and in the delivery pipe.

$$
E U E=\frac{E_{P}}{E_{P V}}
$$

where: $E_{P}$ is the energy effectively used to pump water to the tank (kWh), $E_{P V}$ is the total energy produced by the PV system ( $\mathrm{kWh}$ ), calculated by the model as described in Section 2.2.1. $E_{P}$ can be calculated by applying Equation (15).

$$
E_{P}=\frac{\gamma \cdot H \cdot V_{P}}{3600000}
$$

where: $V_{P}$ is the total volume of water pumped $\left(\mathrm{m}^{3}\right)$ and $H$ is the pumping head (m).

The volume of water pumped for the optimal solution was $39,484.9 \mathrm{~m}^{3}$. The increase in the water level between the well and the tank was $38 \mathrm{~m}$. The increasing of the potential energy of the water accumulated in the tank (net energy received by the water) was $4088.660063 \mathrm{kWh}$. The potential energy produced by the PV plant as a function of the irradiance was $21,657.46 \mathrm{kWh}$. The resulting EUE for the minimum cost design was thus $18.88 \%$. These results are similar to those found by Zavala et al. [37] for a direct pumping system without storage.

As discussed before, EUE is low, which implies that much of the potential PV energy is wasted because the tank is often full due to low storage capacity. The EUE could be increased if the storage capacity were increased. To illustrate this scenario, we simulated the system performance for increased values of storage capacity. For each storage value, we determined the minimum required peak power of the PV plant and the EUE was then calculated. Figure 7 depicts these relationships. It can be seen that as the storage volume increases from $420 \mathrm{~m}^{3}$ (economically optimal design), the peak power of the PV plant decreases and the EUE rises. To illustrate this effect, for a storage capacity of $10,000 \mathrm{~m}^{3}$, the peak power of the plant reduces almost half its value for $420 \mathrm{~m}^{3}$ and EUE increases up to $40 \%$.

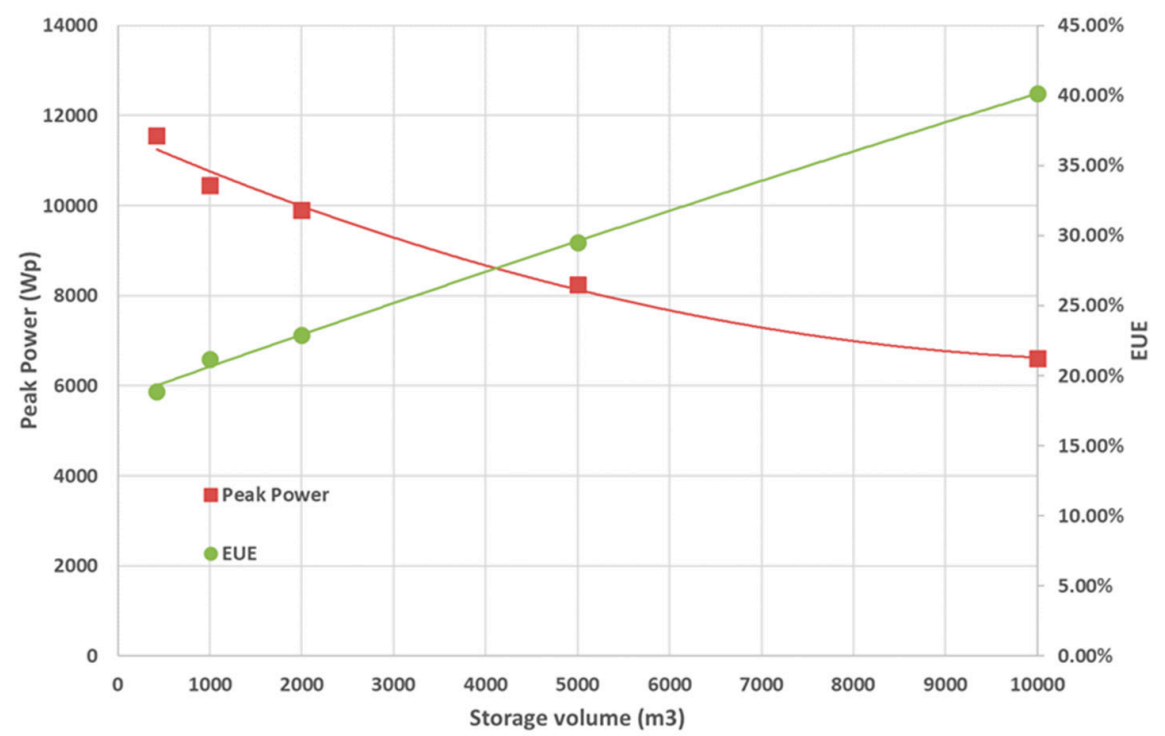

Figure 7. Required minimum peak power of the PV plant and resulting Energy Use Efficiency (EUE) for increased values of tank storage capacity. 
According to these results, minimizing the system cost should not be the only objective to optimize the performance of the system, increasing the EUE should be considered as well. A multiobjective optimization approach with two objectives, i.e., minimizing cost and maximizing EUE, is strongly recommended for future research in order to obtain balanced designs with the optimal trade-off between efficiency and cost.

\section{Conclusions}

In this study, a new heuristic method based on a hybrid approach and a search space reduction has been developed and adapted to the optimal design of stand-alone PV irrigation pumping to a storage tank. The proposed approach is based on iteratively bounding the search space by applying engineering-based rules to the problem with the aim of reducing the number of possible scenarios to analyze and applying a genetic algorithm to the reduced search space. This methodology has been applied to find the optimal design of a benchmark PV irrigation system with storage for a real farm located in Tabernas in the province of Almería (Spain).

A considerable reduction of the search space was accomplished with the proposed methodology, which also provided a much faster and accurate convergence.

The total cost of the PV irrigation system was considerably reduced. This study proved that the most sensitive variables were the number of modules and the type of pump, whereas the diameter of the pipe and volume of the storage tank remained more stable.

It has been proven that minimizing the system cost may result in low energy use efficiency (EUE). To overcome this situation, a multiobjective optimization approach considering two objectives, i.e., minimizing cost and maximizing EUE, is strongly recommended for future research in order to obtain balanced designs with the optimal trade-off between efficiency and cost.

Supplementary Materials: Supplementary materials contain the description of the proposed case study with the aim of providing a benchmark system to test and enable comparison with other methods applied to the optimal design of a Photovoltaic irrigation system with storage. Supplementary materials are composed of a single Excel workbook containing the pump and pipe databases used in this research along with the storage cost function. The following are available online at http://www.mdpi.com/2071-1050/12/3/1026/s1.

Author Contributions: Investigation, data curation J.M. and J.I.M.; formal analysis, data curation, writing-original draft preparation, J.R. and R.L.-L.; formal analysis, validation, methodology, J.R.; R.L.-L.; J.M. and J.I.M. conceptualization, writing-review and editing, project administration, J.R. and R.L.-L. All authors have read and agreed to the published version of the manuscript.

Funding: This research was funded by the Spanish Ministry for Science, Innovation and Universities program RETOS INVESTIGACIÓN under the project RIDESOST (AGL2017-85857-C2-1-R).

Acknowledgments: We want to acknowledge the supporters of this research.

Conflicts of Interest: The authors declare no conflict of interest.

\section{References}

1. Yahyaoui, I.; Chaabene, M.; Tadeo, F. Energy Management for Photovoltaic Irrigation with a Battery Bank. Int. J. Energy Optim. Eng. 2015, 4, 18-32. [CrossRef]

2. Posadillo, R.; López Luque, R. A sizing method for stand-alone PV installations with variable demand. Renew. Energy 2008, 33, 1049-1055. [CrossRef]

3. Yahyaoui, I.; Yahyaoui, A.; Chaabene, M.; Tadeo, F. Energy management for a stand-alone photovoltaic-wind system suitable for rural electrification. Sustain. Cities Soc. 2016, 25, 90-101. [CrossRef]

4. Glasnovic, Z.; Margeta, J. A model for optimal sizing of photovoltaic irrigation water pumping systems. Sol. Energy 2007, 81, 904-916. [CrossRef]

5. Campana, P.E.; Li, H.; Yan, J. Dynamic modelling of a PV pumping system with special consideration on water demand. Appl. Energy 2013, 112, 635-645. [CrossRef]

6. Gao, X.; Liu, J.; Zhang, J.; Yan, J.; Bao, S.; Xu, H.; Qin, T. Feasibility evaluation of solar photovoltaic pumping irrigation system based on analysis of dynamic variation of groundwater table. Appl. Energy 2013, 105, 182-193. [CrossRef] 
7. López-Luque, R.; Reca, J.; Martínez, J. Optimal design of a standalone direct pumping photovoltaic system for deficit irrigation of olive orchards. Appl. Energy 2015, 149, 13-23. [CrossRef]

8. Reca, J.; Torrente, C.; López-Luque, R.; Martínez, J. Feasibility analysis of a standalone direct pumping photovoltaic system for irrigation in Mediterranean greenhouses. Renew. Energy 2016, 85, 1143-1154. [CrossRef]

9. Mérida, A.; Fernández, I.; Camacho, E.; Montesinos, P.; Rodríguez, J.A. Coupling irrigation scheduling with solar energy production in a smart irrigation management system. J. Clean. Prod. 2018, 175, 670-682. [CrossRef]

10. López-Luque, R.; Martínez, J.; Reca, J.; Ruiz, R. Análisis de viabilidad y gestión del riego en invernaderos mediterráneos con energía solar fotovoltaica. Ribagua 2017, 74-83. [CrossRef]

11. Hamidat, A.; Benyoucef, B. Systematic procedures for sizing photovoltaic pumping system, using water tank storage. Energy Policy 2009, 37, 1489-1501. [CrossRef]

12. Reca, J.; García-Manzano, A.; Martínez, J. Optimal pumping scheduling model considering reservoir evaporation. Agric. Water Manag. 2015, 148, 250-257. [CrossRef]

13. Yahyaoui, I.; Tadeo, F.; Segatto, M.V. Energy and water management for drip-irrigation of tomatoes in a semiarid district. Agric. Water Manag. 2017, 183, 4-15. [CrossRef]

14. Campana, P.E.; Li, H.; Zhang, J.; Zhang, R.; Liu, J.; Yan, J. Economic optimization of photovoltaic water pumping systems for irrigation. Energy Convers. Manag. 2015, 95, 32-41. [CrossRef]

15. Bouzidi, B. New sizing method of PV water pumping systems. Sustain. Energy Technol. Assess. 2013, 4, 1-10. [CrossRef]

16. Maleki, A.; Askarzadeh, A. Artificial bee swarm optimization for optimum sizing of a stand-alone PV/WT/FC hybrid system considering LPSP concept. Sol. Energy 2014, 107, 227-235. [CrossRef]

17. Maleki, A.; Pourfayaz, F. Optimal sizing of autonomous hybrid photovoltaic/wind/battery power system with LPSP technology by using evolutionary algorithms. Sol. Energy 2015, 115, 471-483. [CrossRef]

18. Holland, J.H. Adaptation in Natural and Artificial Systems; MIT Press: Cambridge, MA, USA, 1975.

19. Maleki, A.; Ameri, M.; Keynia, F. Scrutiny of multifarious particle swarm optimization for finding the optimal size of a PV/wind/battery hybrid system. Renew. Energy 2015, 80, 552-563. [CrossRef]

20. Sanchez, V.M.; Chavez-Ramirez, A.U.; Duron-Torres, S.M.; Hernandez, J.; Arriaga, L.G.; Ramirez, J.M. Techno-economical optimization based on swarm intelligence algorithm for a stand-alone wind-photovoltaic-hydrogen power system at south-east region of Mexico. Int. J. Hydrogen Energy 2014, 39, 16646-16655. [CrossRef]

21. Bakelli, Y.; Kaabeche, A. Optimal size of photovoltaic pumping system using nature-inspired algorithms. Int. Trans. Electr. Energy Sys. 2019, 29, e12045. [CrossRef]

22. Olcan, C. Multi-objective analytical model for optimal sizing of stand-alone photovoltaic water pumping systems. Energy Convers. Manag. 2015, 100, 358-369. [CrossRef]

23. El-Shimy, M. Sizing optimisation of stand-alone photovoltaic generators for irrigation water pumping systems. Int. J. Sustain. Energy 2013, 32, 333-350. [CrossRef]

24. Dufo-López, R.; Bernal-Agustín, J.L. Design and control strategies of PV-Diesel systems using genetic algorithms. Sol. Energy 2005, 79, 33-46. [CrossRef]

25. Carroquino, J.; Dufo-López, R.; Bernal-Agustín, J.L. Sizing of off-grid renewable energy systems for drip irrigation in Mediterranean crops. Renew. Energy 2015, 76, 566-574. [CrossRef]

26. Ma, T.; Yang, H.; Lu, L.; Peng, J. An Optimization Sizing Model for Solar Photovoltaic Power Generation System with Pumped Storage. Energy Procedia 2014, 61, 5-8. [CrossRef]

27. Mérida García, A.; González Perea, R.; Camacho Poyato, E.; Montesinos Barrios, P.; Rodríguez Díaz, J.A. Comprehensive sizing methodology of smart photovoltaic irrigation systems. Agric. Water Manag. 2020, 229, 105888. [CrossRef]

28. Reca, J.; Martínez, J.; López, R. A Hybrid Water Distribution Networks Design Optimization Method Based on a Search Space Reduction Approach and a Genetic Algorithm. Water 2017, 9, 845. [CrossRef]

29. Duffie, J.A.; Beckman, W.A. Solar Engineering of Thermal Process, 3rd ed.; John Wiley \& Sons: Hoboken, NJ, USA, 2006.

30. Collares-Pereira, M.; Rabl, A. The average distribution of solar radiation-correlations between diffuse and hemispherical and between daily and hourly insolation values. Sol. Energy 1979, 22, 155-164. [CrossRef] 
31. Reca, J.; López, R. Chapter 9-Design Principles of Photovoltaic Irrigation Systems. In Advances in Renewable Energies and Power Technologies; Yahyaoui, I., Ed.; Elsevier Science: Amsterdam, The Netherlands, 2018; pp. 295-333. [CrossRef]

32. Bhave, P.R. Analysis of Flow in Water Distribution Networks; Technomic Publishing Co. Inc.: Lancaster, Basel, Switzerland, 1991.

33. Allen, R.G.; Pereira, L.S.; Raes, D.; Smith, M. Crop evapotranspiration-Guidelines for Computing Crop Water Requirements; FAO Irrigation and Drainage Paper 56; Food and Agriculture Organization of the United Nations: Rome, Italy, 1998.

34. Dastane, N.G. Effective Rainfall in Irrigated Agriculture; FAO Irrigation and Drainage Paper 25; Food and Agriculture Organization of the United Nations: Rome, Italy, 1976.

35. Reca, J.; Martínez, J. Genetic algorithms for the design of looped irrigation water distribution networks. Water Resour. Res. 2006, 42, W05416. [CrossRef]

36. Wu, Z.Y; Walski, T. Self-Adaptive Penalty Approach Compared with Other Constraint-Handling Techniques for Pipeline Optimization. J. Water Resour. Plan. Manag. 2005, 131, 181-192. [CrossRef]

37. Zavala, V.; López-Luque, R.; Reca, J.; Martínez, J.; Lao, M.T. Optimal management of a multisector standalone direct pumping photovoltaic irrigation system. Appl. Energy 2020, 260, 114261. [CrossRef]

(C) 2020 by the authors. Licensee MDPI, Basel, Switzerland. This article is an open access article distributed under the terms and conditions of the Creative Commons Attribution (CC BY) license (http://creativecommons.org/licenses/by/4.0/). 